\title{
Peripheral Ossifying Fibroma: A Case Report
}

\author{
Dr. Barun Kumar Sah, ${ }^{1}$ Dr. Bandana Koirala, ${ }^{2}$ Dr. Mamta Dali, ${ }^{2}$ Dr. Sneha Shrestha ${ }^{2}$ \\ ${ }^{1}$ Department of Pediatric and Preventive Dentistry, People's Dental College and Hospital, Kathmandu, Nepal \\ ${ }^{2}$ Department of Pedodontics and Preventive Dentistry, CODS, B.P.K.I.H.S., Dharan, Nepal
}

\begin{abstract}
Peripheral ossifying fibroma (POF) is a common solitary gingival growth thought to arise from the periodontal ligament. Though the etiology of POF remains unknown, some investigators consider it an inflammatory or reactive process, while others suggest it is a neoplastic process. Here, we present a case of POF in a 10-year-old boy, affecting the maxillary anterior gingiva along with its clinical, radiographic, histologic characteristics, differential diagnosis, treatment and one year follow-up.

Keywords: Fibroma; gingival growth; peripheral ossifying fibroma (POF).
\end{abstract}

\section{INTRODUCTION}

Peripheral ossifying fibroma (POF) is a reactive, inflammatory, hyperplastic soft tissue growth believed to arise from the gingiva, periosteum, and the periodontal membrane. It comprises about $9 \%$ of all gingival growths and is usually seen on the interdental papilla. The lesions are usually small, located in the anterior maxilla and occur more commonly in the second decade with a female predilection. ${ }^{1}$ After elimination of the local etiological factors, local surgical excision including the periodontal ligament and periosteum at the base of the lesion is the preferred treatment in order to reduce the chance of recurrence. POF shows a clinically benign behavior. However, the recurrence rates of $8 \%$ to $20 \%$ have been reported. ${ }^{2,3}$

\section{CASE REPORT}

A healthy 10 years old boy reported to the Department of Pedodontics and Preventive Dentistry, CODS, B.P.K.I.H.S. Dharan with chief complaints of slow growing painless mass in upper front teeth region noticed since three months. The lesion started as a small nodule that progressed gradually to present size within period of three months. It was not associated with any local discomfort. Intra oral examination revealed, a small pedunculated soft tissue mass firm in

\footnotetext{
Correspondence:

Dr. Barun Kumar Sah

Department of Pediatric and Preventive Dentistry

People's Dental College and Hospital, Kathmandu, Nepal

Email: drbarunsh@gmail.com

Citation

Sah BK, Koirala B, Dali M, Shrestha S. Peripheral Ossifying Fibroma: A Case Report. J Nepal Soc Perio Oral Implantol. 2020;4(7):39-42

DOI: https://doi.org/10.3126/jnspoi.v4i1.30903
}

consistency, non-tender on palpation, pink in color of size approximately $0.6 \times 0.5$ sq. cm. extending from attached gingiva to alveolar mucosa of upper right lateral incisor (Figure 1). The maxillary occlusal view (Figure 2) and intra oral peri-apical radiograph IOPAR (Figure 3) were within normal limits. The oral hygiene status was fair.

Based on history and clinical examination, a provisional diagnosis of POF was made. The differential diagnosis consisted of peripheral giant cell granuloma, pyogenic granuloma, fibroma and peripheral odontogenic fibroma.

Under local anaesthesia, excisional biopsy of the lesion was performed (Figure 4). 3-0 black braided silk suture (Figure 5) was placed and wound was covered with coe-pack (Figure 6). The excised tissue (Figure 7) was sent for histo-pathological examination. After one week, the healing was uneventful. (Figure 8). The patient was reviewed at six months (Figure 9) and one year (Figure 10) with no signs of recurrence.

The histo-pathological findings revealed an atrophic parakeratinised stratified squamous epithelium with no significant rete ridges overlying a dense fibrous connective tissue stroma comprising of thick bundles of collagen fibers

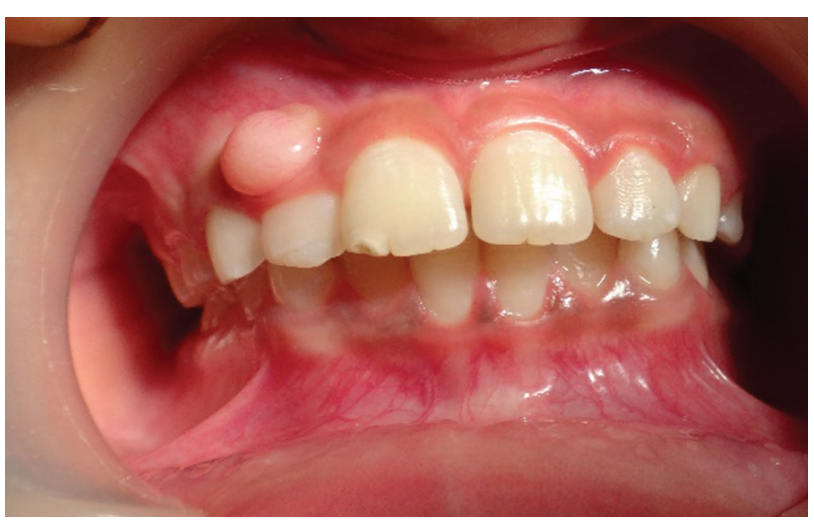

Figure 1: Pre-op. 


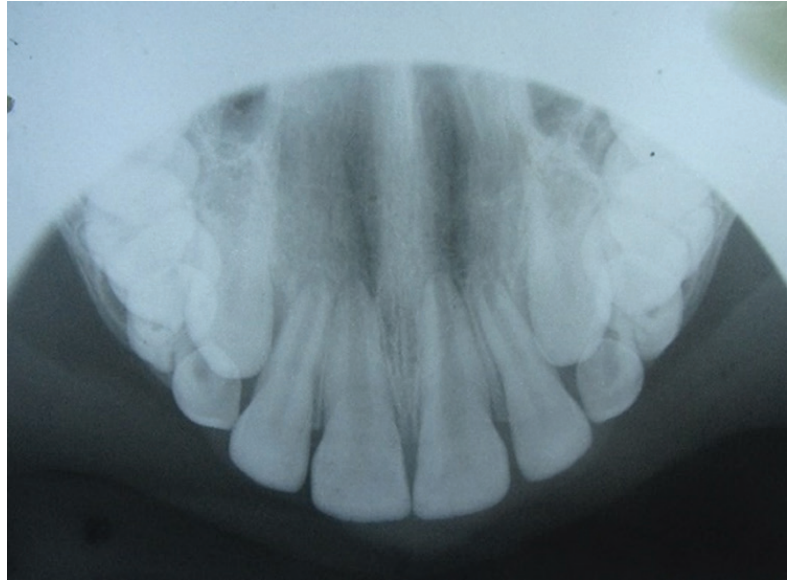

Figure 2: Pre-op maxillary occlusal view.

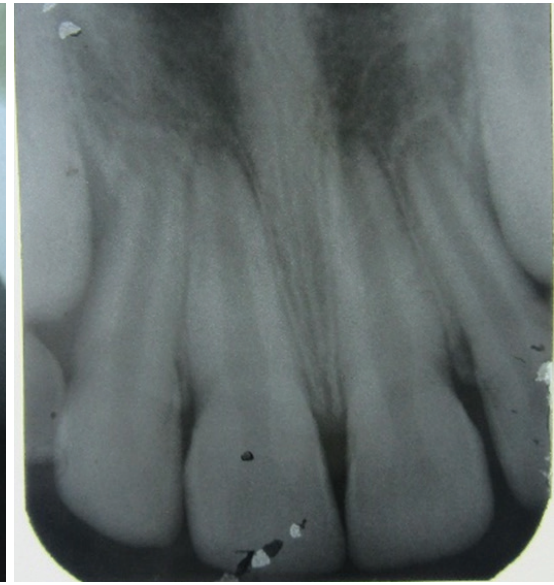

Figure 3: Pre-op IOPAR.

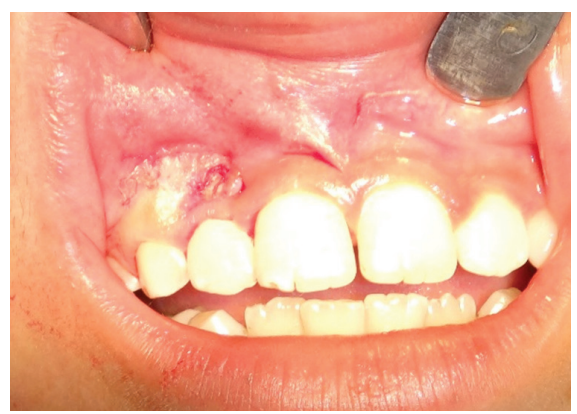

Figure 4: After excision of mass.

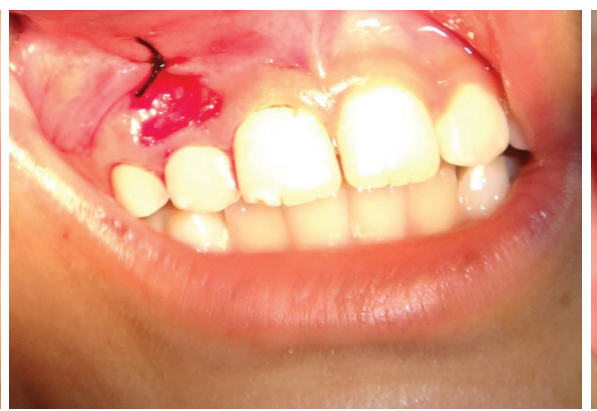

Figure 5: After suture Placement.

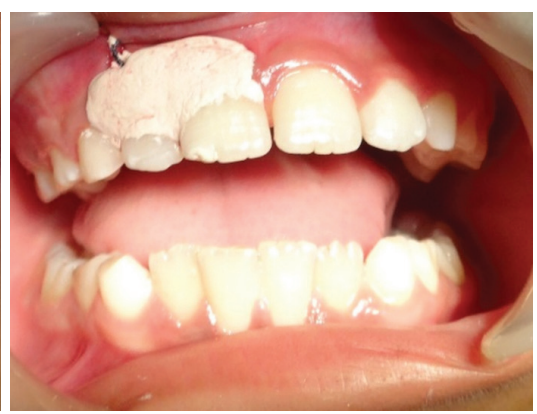

Figure 6: After Coe-Pack Placement.

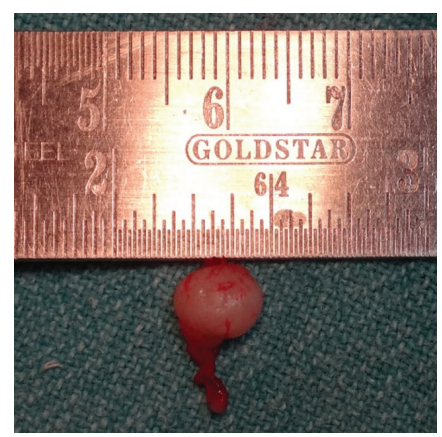

Figure 7: Excised mass.

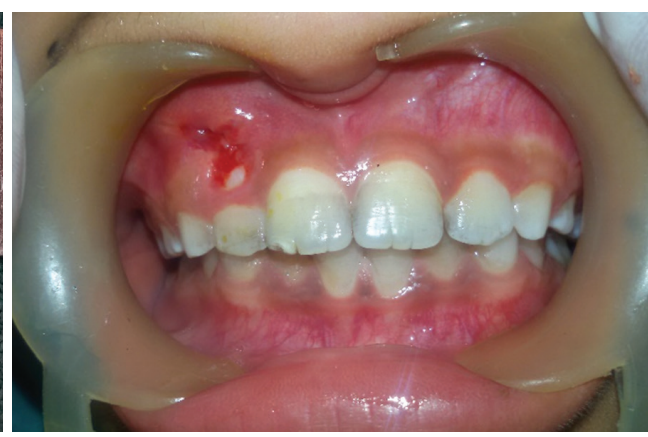

Figure 8: After 1 week.

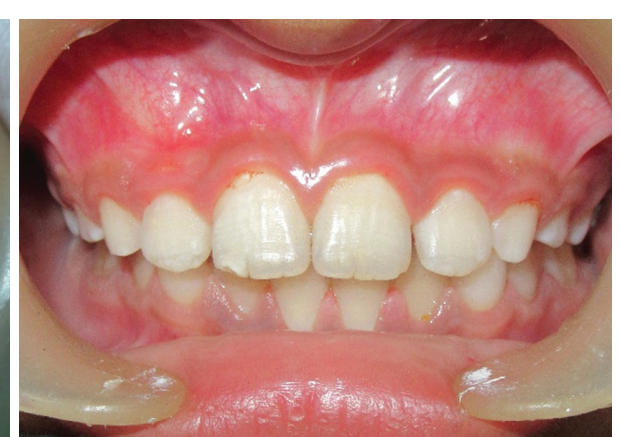

Figure 9: After six months.

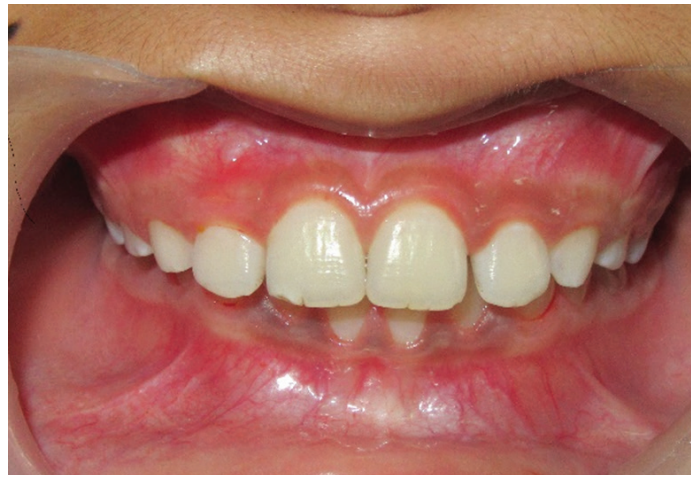

Figure 10: After 12 months.

and interspersed numerous fibroblasts and fibrocytes. Infrequent endothelial cells lined blood vessels were evident. A focal area revealed a mineralised bony tissue with osteocytes within a lacunae suggestive of POF (Figure 11).

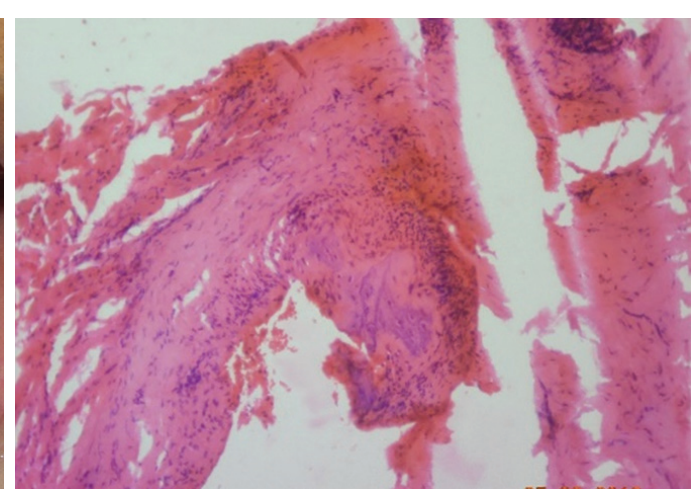

Figure 11: Histological image.

\section{DISCUSSION}

POF is typically a solitary, slowly growing nodular mass that is either pedunculated or sessile. The surface mucosa is usually smooth or ulcerated and pink to red in color. The migration 
of teeth with interdental bone loss has been reported in some cases. POF usually measures less than $1.5 \mathrm{~cm}$ in diameter, but patients with lesions of $6 \mathrm{~cm}$ and $9 \mathrm{~cm}$ diameter have been reported. ${ }^{2}$ The color and size of the lesion in this case is similar to that reported in literature. ${ }^{3}$

POF is thought to be either reactive or neoplastic in nature. Considerable confusion has prevailed in the nomenclature of peripheral ossifying fibroma with various synonyms being used, such as peripheral cementifying fibroma, ossifying fibroepithelial polyp, peripheral fibroma with osteogenesis, peripheral fibroma with cementogenesis, peripheral fibroma with calcification, calcifying or ossifying fibroma epulis, and calcifying fibroblastic granuloma. ${ }^{4}$

There are two types of ossifying fibromas: central type and peripheral type. The central type arises from endosteum or periodontal ligament adjacent to root apex and causes expansion of medullary cavity. The peripheral type occurs solely on soft tissues covering tooth-bearing areas of the jaws. ${ }^{5}$

POF accounts for $3.1 \%$ of all oral tumors and $9.6 \%$ of gingival lesions. This condition affects both genders but has been reported to occur at a higher rate in females. Whites (71\%) are more frequently affected than blacks (36\%). POF may occur at various ages, but exhibits a peak incidence between the second and third decade. ${ }^{6}$ But in this case, lesion is present in male patient in first decade which is a bit of variation as from the reports in the literature.

The etiology and pathogenesis of POF are not known. It has been suggested that these lesions originate in cells of the periodontal ligament for the following reasons: POF exclusively appears in the gingival tissue, close to the periodontal ligament; oxytalan fibers are found within the mineralised matrix of some lesions; the age distribution of the lesions is inversely proportional to the number of permanent teeth lost; and the fibrocellular response of POF is similar to that of other reactive gingival lesions originating in the periodontal ligament. ${ }^{3}$

Eversole and Rovin stated that constant irritation present during exfoliation of deciduous teeth and eruption of permanent teeth may result in increased incidence of reactive lesions originating from periodontal ligament. Apart from this, other possible cited causes include trauma or irritants such as calculus, plaque, microorganisms, dental appliances and ill-fitting crowns. ${ }^{7}$ In this case, the local irritants might have been the cause of growth.
In pediatric patient studies, the incidence of POF in biopsied lesions from all oral sites has ranged from $1 \%$ to $2 \%$ and out of 134 pediatric patients with POF in only 2 cases POF was intimately associated with primary teeth, bringing into question the reactivity of the lesion. In surveys limited to gingival biopsy specimens that have included both adults and children, the reported incidence is in the $9 \%$ to $10 \%$ range. $^{8}$

The lesion may be present for months to years before the treatment, depending on the degree of ulceration, discomfort and interference with function. Approximately 60\% of POF occur in the maxilla. They occur more often in the anterior than the posterior area with 55\%-60\% presenting in the incisor-cuspid region. ${ }^{9}$

Radiographic features of POF vary. Radiopaque foci of calcifications have been reported to be scattered in central area of the lesion, but not all lesions demonstrate radiographic calcifications. Underlying bone involvement is usually not visible on a radiograph. In rare instances, superficial erosion of bone is noted. ${ }^{4}$ In the present case no radiographic evidence of bone involvement was evident.

A definitive diagnosis of POF is made by histopathologic evaluation of biopsy specimens. The features usually observed during microscopic examination are intact or ulcerated stratified squamous surface epithelium, benign fibrous connective tissue with varying numbers of fibroblasts, sparse to profuse proliferation, mineralised material consisting of mature, lamellar or woven osteoid, cementum-like material, or dystrophic calcifications; and acute or chronic inflammatory cells in lesions. ${ }^{2,4}$ Most of the above mentioned features were seen in this case.

To avoid recurrence, treatment requires proper surgical intervention that ensures deep excision of the lesion including periosteum. Thorough scaling and root planing of adjacent teeth and/or removal of other sources of irritants should be accomplished ${ }^{9}$ which was performed here. The recovery was uneventful and showed no any signs of recurrence up to a period of one year.

\section{ACKNOWLEDGMENTS}

We would like to thank Department of Oral Biology, CODS, B.P.K.I.H.S., Nepal for rendering assistance in histology specimen preparation and staining.

\section{Conflict of interest: None}




\section{REFERENCES}

1. Agarwal P, Chug A, Kumar S, Jain K. Palatal peripheral ossifying fibroma: A rare occurrence. Int J Health Sci (Qassim). 2019;13(4):63-6.

2. Kumar SKS, Ram S, Jorgensen MG, Shuler CF, Sedghizadeh PP. Multicentric peripheral ossifying fibroma. J Oral Sci. 2006 Dec;48(4):239-43.

3. Chhina S, Rathore AS, Ahuja P. Peripheral ossifying fibroma of gingiva: A case report. IJCRI-International J Case Reports Images. 2011;2(11):21-4.

4. Yadav R, Gulati A. Peripheral ossifying fibroma: a case report. J Oral Sci. 2009;51(1):151-4.

5. Keluskar V, Byakodi R, Shah N. Peripheral ossifying fibroma. J Indian Acad Oral Med Radiol. 2008;20(2):54-6.

6. Pal S, Hegde S, Ajila V. The varying clinical presentations of peripheral ossifying fibroma: A report of three cases. Rev Odonto Cienc. 2012;27(3):251-5.

7. Acharya R, Yaseen SM, Yadav S. Peripheral Ossifying Fibroma in Infant: A Case Report. J Dent Probl Solut. 2015;2(2):38-40.

8. Cuisia ZE, Brannon RB. Peripheral ossifying fibroma - A clinical evaluation of 134 pediatric cases. Pediatr Dent. 2001;23(3):245-8.

9. Shetty P, Adyanthaya S. Peripheral Ossifying Fibroma-A Clinical and Histological Evaluation of 51 Cases. PJSR. 2012;5(1):9-14. 